\title{
Successful Intracoronary Thrombolysis in Acute ST Elevation Myocardial Infarction Patient With Uncorrected Tetralogy of Fallot
}

\author{
Tan Quang Phan a, b, d, Hieu Lan Nguyenc, Thang Duy Nguyenc, Sang Wook Kim ${ }^{\mathrm{b}}$
}

\begin{abstract}
Tetralogy of Fallot (TOF) is the most common cyanotic congenital heart disease that has low survival rate without surgical correction. This report is about a rare case of acute ST elevation myocardial infarction in a 46-year-old patient with uncorrected TOF that was successfully treated with low-dose intracoronary thrombolysis.
\end{abstract}

Keywords: Tetralogy of Fallot; Acute myocardial infarction; Percutaneous intervention; Intracoronary thrombolysis

\section{Introduction}

Tetralogy of Fallot (TOF) is the most common cyanotic congenital heart disease in infant, accounting for about $10 \%$ of all congenital heart diseases in the USA. Thanks to the development of cardiovascular surgery for congenital heart diseases, most of TOF patients are currently corrected surgically. Without surgical correction, the survival rate of TOF patients is very low and only less than $3 \%$ of the TOF patients could survive to the age of 40 [1]. Due to the progressive nature of TOF, the older these patients are, the higher risk of thromboembolic complications they may also encounter $[2,3]$. We hereby present a rare case of percutaneous coronary intervention (PCI) for acute ST elevation myocardial infarction (STEMI) in a TOF patient who had survived till the age of 46 years without any cardiac surgery.

Manuscript submitted November 5, 2020, accepted December 2, 2020

Published online January 19, 2021

${ }^{a}$ Cardiovascular Intervention Department, Quang Nam Central Hospital, Quang Nam 562409, Vietnam

${ }^{\mathrm{b} C a r d i o v a s c u l a r}$ Research Center, Chung-Ang University Hospital, Seoul 06973, South Korea

${ }^{\mathrm{c} C a r d i o v a s c u l a r}$ Center, Hanoi Medical University Hospital, Hanoi 100000 Vietnam

${ }^{\mathrm{d} C o r r e s p o n d i n g ~ A u t h o r: ~ T a n ~ Q u a n g ~ P h a n, ~ C a r d i o v a s c u l a r ~ I n t e r v e n t i o n ~ D e-~}$ partment, Quang Nam Central Hospital, Quang Nam 562409, Vietnam.

Email: quangft@gmail.com

doi: https://doi.org/10.14740/jmc3619

\section{Case Report}

A 46-year-old male patient was admitted to our hospital due to chest pain. Even though he had a history of TOF diagnosed since he was a child, he could get married and have two healthy children. Before hospitalization, he suddenly felt squeezing chest pain that was persistent for $2 \mathrm{~h}$. Examination showed minimal cyanosis, clubbing on the extremities and systolic murmur along the left sternal border. There was ST elevation in leads II, III, aVF along with incomplete right bundle branch block, a right axis deviation and right ventricular hypertrophy on electrocardiogram (ECG). Transthoracic echocardiography revealed typical signs of TOF (Fig. 1). Cardiac troponin T was increased $(2,999 \mathrm{ng} / \mathrm{mL})$.

The patient was diagnosed with STEMI and received standard medications, including aspirin, clopidogrel, rosuvastatin, nitroglycerin, and enoxaparin. Emergency coronary angiography showed total occlusion of a large right coronary artery (RCA) from second segment (Fig. 2). Thrombus aspiration with catheter was performed multiple times and a lot of thrombus was sucked from RCA. However, after thrombus aspiration, there was still significant thrombus in second and third segment of RCA, with thrombolysis in myocardial infarction (TIMI) flow grade 2 on coronary angiogram. Because

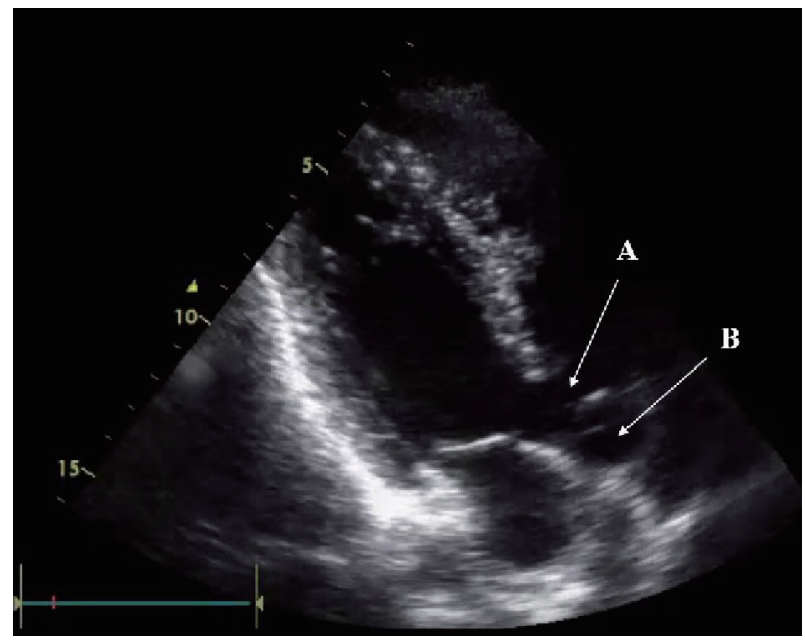

Figure 1. Echocardiography showing tetralogy of Fallot with ventricular septal defect (arrow A) and overriding of the aorta (arrow B). 


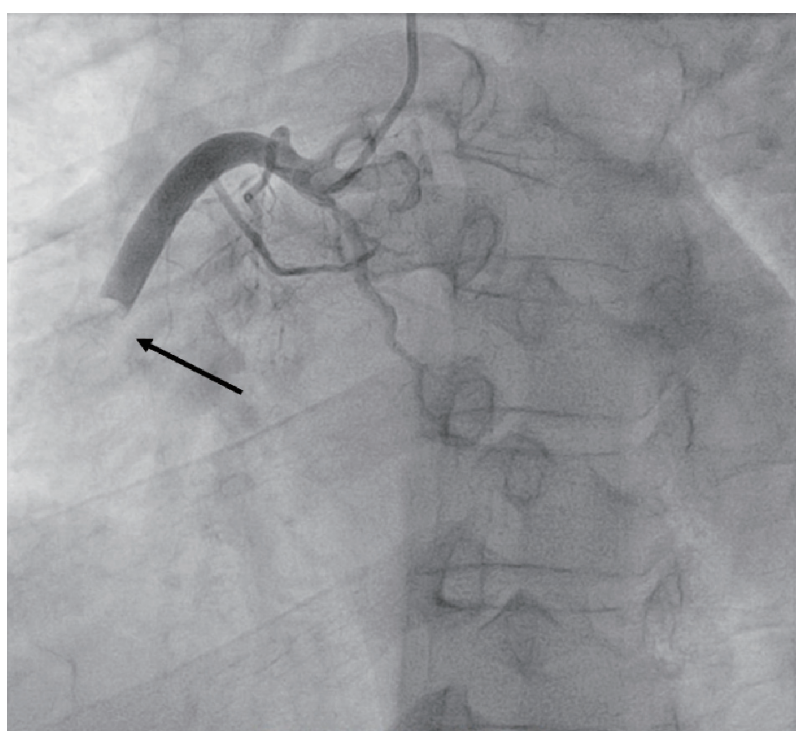

Figure 2. Right coronary artery angiogram revealing total occlusion of the right coronary artery at the second segment (arrow).

there was no obvious lesion that could be seen and the diameter of RCA was $7.0 \mathrm{~mm}$ by quantitative coronary analysis, the stenting or ballooning seemed to be unreasonable. So, we decided to perform intracoronary thrombolytic therapy with $25 \mathrm{mg}$ of alteplase directly through the guiding catheter for 5 min. Follow-up coronary angiography $24 \mathrm{~h}$ after the procedure revealed completely dissolved of thrombus with TIMI 3 flow (Fig. 3).

After the procedure, the complete blood count showed erythrocytosis with red blood cells of $5.93 \times 10^{12} / \mathrm{L}$, hemoglobin of $202 \mathrm{~g} / \mathrm{L}$, hematocrit of 0.58 , and normal white blood cells and platelet. Blood pressure was 90/60 $\mathrm{mm} \mathrm{Hg}$ without inotrope or vasopressor. So, saline infusion with total volume of 2,000 mL was performed for 3 days. The follow-up hematocrit was reduced to 0.45 and blood pressure increased to 120/80 mm Hg. Holter ECG after the procedure revealed sinus tachycardia without atrial fibrillation, flutter or atrial-ventricular block. Cardiac computed tomography (CT) showed typical TOF with $10 \mathrm{~mm}$ ventricular septal defect (VSD) and severe supravalvular pulmonary stenosis. The patient was discharged 10 days after the procedure on standard medications for STEMI.

\section{Discussion}

In patients with uncorrected TOF, excessive erythrocytosis and blood hyperviscosity resulted from chronic hypoxemia increases the risk of thromboembolic complications [3, 4]. Even though these complications can occur in both artery and vein, most of reported thromboembolic events were related to ischemic stroke [4-6]. Acute myocardial infarction in patients with uncorrected TOF was rarely mentioned in the literature.

In our patient, the total occlusion of RCA seemed to be more likely secondary from thromboembolism because the

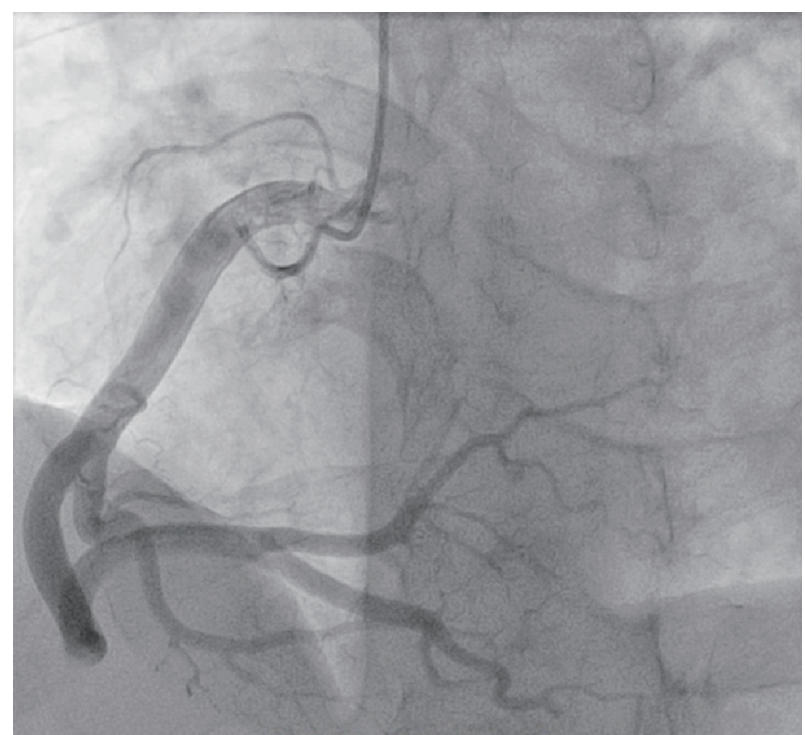

Figure 3. Follow-up right coronary artery angiogram $24 \mathrm{~h}$ after thrombolysis.

coronary angiogram after thrombus aspiration and thrombolysis showed no significant stenosis of a very large coronary artery. Although the 24-h Holter ECG after intervention detected only sinus rhythm and there was no arrhythmia noticed during 10 days of hospitalization, we could not exclude the possibility of proximal atrial fibrillation that can trigger thrombus formation and coronary artery occlusion in this patient. On the other hand, thrombus formation might be accelerated by the excessive erythrocytosis and blood hyperviscosity complicated from TOF in this patient $[7,8]$.

Massive thrombus in coronary artery, defined as angiographic finding of TIMI thrombus grade (TTG) $4-5$, has been reported with an incidence of $16-17 \%$ in acute coronary syndrome [9]. Recommended procedure for those patients during PCI was firstly catheter thrombus aspiration to reduce thrombus burden before next decisions. In cases of failure with thrombus aspiration, defined as TTG $\geq 2$, distal embolization or slow-flow, intracoronary thrombolysis could be a good additional therapy [10-13]. Thrombolytic agents and their doses were different among reports, which could be streptokinase, alteplase, tenecteplase, etc., at full or reduced dose in comparison with systemic venous thrombolysis. The complete dissolving or significant reduction of thrombus at the main vessel as well as microvascular bed seemed to improve in epicardial flow and tissue-level perfusion, and therefore improve the outcomes of the intervention [14]. Importantly, because thrombolysis therapy also has tendency of severe complications, especially major bleeding, careful patient selection strictly based on contemporary recommendations is very important to reduce adverse events. Because our patient was an only $55-\mathrm{kg}$ male with erythrocytosis complicated form cyanotic congenital heart disease and already received loading dose of antiplatelet and anticoagulants for STEMI, the risk of major bleeding might be greatly increased. So, we decided to use only low dose of alteplase $(25 \mathrm{mg})$, which was only a quarter of recommend- 
ed dose of this agent for systemic thrombolytic in STEMI. Even though, after intracoronary administration of low dose alteplase, thrombus was completely dissolved, demonstrated with TIMI 3 flow in the RCA.

\section{Conclusions}

Although rare, STEMI secondary from thromboembolism can occur in uncorrected TOF patients at advanced age. In patients with large thrombus burden and high risk of major bleeding, the low dose of thrombolytic agents may be safe and efficacious.

\section{Learning points}

Learning points from this case include: 1) Acute myocardial infarction can occur in uncorrected TOF patient, especially at the advanced age that needs to be quickly diagnosed and proper treatment; 2) The low dose of thrombolytic agents may be safe and efficacious in STEMI patients with uncorrected TOF after failure of thrombus aspiration.

\section{Acknowledgments}

None to declare.

\section{Financial Disclosure}

None to declare.

\section{Conflict of Interest}

None to declare.

\section{Informed Consent}

The patient gave written informed consent before case report publication.

\section{Author Contributions}

All authors have contributed towards the drafting of the case report and offered comments to the previous versions for important content. The main draft of manuscript was written by Phan Tan Quang (primary author).

\section{Data Availability}

The authors declare that data supporting the findings of this study are available within the article.

\section{Abbreviations}

PCI: percutaneous coronary intervention; TOF: tetralogy of Fallot; STEMI: ST elevation myocardial infarction; RCA: right coronary artery; TIMI: thrombolysis in myocardial infarction; TTG: TIMI thrombus grade

\section{References}

1. Bertranou EG, Blackstone EH, Hazelrig JB, Turner ME, Kirklin JW. Life expectancy without surgery in tetralogy of Fallot. Am J Cardiol. 1978;42(3):458-466.

2. Makaryus AN, Aronov I, Diamond J, Park CH, Rosen SE, Stephen B. Survival to the age of 52 years in a man with unrepaired tetralogy of Fallot. Echocardiography. 2004;21(7):631-637.

3. Bond JH, Jr., Sarosi GA, Bache RJ. Acute myocardial infarction in a patient with tetralogy of Fallot. Arch Intern Med. 1969;123(4):439-440.

4. Kwaan HC, Wang J. Hyperviscosity in polycythemia vera and other red cell abnormalities. Semin Thromb Hemost. 2003;29(5):451-458.

5. Ali H, Sarfraz S, Sanan M. Tetralogy of Fallot: Stroke in a Young Patient. Cureus. 2018;10(5):e2714.

6. Coutu M, Poirier NC, Dore A, Carrier M, Perrault LP. Late myocardial revascularization in patients with tetralogy of Fallot. Ann Thorac Surg. 2004;77(4):14541455.

7. Rose SS, Shah AA, Hoover DR, Saidi P. Cyanotic congenital heart disease (CCHD) with symptomatic erythrocytosis. J Gen Intern Med. 2007;22(12):1775-1777.

8. Swan L, Hillis WS. Management of polycythaemia in adults with cyanotic congenital heart disease. Heart. 1999;81(4):451

9. Sianos G, Papafaklis MI, Daemen J, Vaina S, van Mieghem CA, van Domburg RT, Michalis LK, et al. Angiographic stent thrombosis after routine use of drug-eluting stents in ST-segment elevation myocardial infarction: the importance of thrombus burden. J Am Coll Cardiol. 2007;50(7):573-583.

10. van 't Hof AW, Liem A, Suryapranata H, Hoorntje JC, de Boer MJ, Zijlstra F. Angiographic assessment of myocardial reperfusion in patients treated with primary angioplasty for acute myocardial infarction: myocardial blush grade. Zwolle Myocardial Infarction Study Group. Circulation. 1998;97(23):2302-2306.

11. Sezer M, Oflaz H, Goren T, Okcular I, Umman B, Nisanci $\mathrm{Y}$, Bilge AK, et al. Intracoronary streptokinase after primary percutaneous coronary intervention. N Engl J Med. 2007;356(18):1823-1834.

12. Kim JS, Kim JH, Jang HH, Lee YW, Song SG, Park JH, Chun KJ. Successful revascularization of coronary artery occluded by massive intracoronary thrombi with alteplase and percutaneous coronary intervention. J Atheroscler Thromb. 2010;17(7):768-770.

13. Boscarelli D, Vaquerizo B, Miranda-Guardiola F, Arzamendi D, Tizon H, Sierra G, Delgado G, et al. Intracoro- 
nary thrombolysis in patients with ST-segment elevation myocardial infarction presenting with massive intraluminal thrombus and failed aspiration. Eur Heart J Acute Cardiovasc Care. 2014;3(3):229-236.

14. Sezer M, Cimen A, Aslanger E, Elitok A, Umman B, Bu- gra Z, Yormaz E, et al. Effect of intracoronary streptokinase administered immediately after primary percutaneous coronary intervention on long-term left ventricular infarct size, volumes, and function. J Am Coll Cardiol. 2009;54(12):1065-1071. 